Chizuko Maeda

University of Alberta

I am lying with my three students, looking at the darkness. It was a few minutes ago that I announced to them that it was time to go to sleep and turned off the light. The romping and chattering which had filled the room until just before I had turned off the light now has ceased and silence seemingly pervades the room. But I know that no one is sleeping. I hear Dai-chan, a thirteen year old boy with Down's syndrome, whispering to Aki, another thirteen-year old boy with Down's syndrome, who is lying next to Dai-chan. Aki says in a low voice, "Ssh Dai-chan, I'm going to sleep." All right, Aki will sleep soon. Dai-chan turns over. I guess he needs more time to fall asleep. Meanwhile, Tetsuro, a fifteen year old boy with cerebral palsy, begins to talk to himself in his usual tone, neither whispering nor loud. "Bath, bath, I took a bath with Mr. H ... I took a bath with Mr. H..." "I like mommy ... I like daddy..." His big eyes wide open, he is fingering his pillow.

His talk continues with a short intermission. "Toshi-chan, Toshi-chan!" He calls Toshi-chan as if he were here. Toshi-chan? I am a little confused. I know, I think to myself, that Tetsuro and Toshi-chan are good friends, but Toshi-chan is not here. Then Tetsuro says, this time, "Dai-chan, Dai-chan!" Dai-chan gets up and turns around to Tetsuro, asking "What, Tetsuro?" Tetsuro doesn't answer. "What did you say, Tetsuro?" Dai-chan whispers again. Tetsuro laughs under his breath but doesn't answer him. Dai-chan lies down again. Tetsuro utters again "Dai-chan ... I like Dai-chan ..." Dai-chan turns his head toward Tetsuro, but doesn't say anything.

After a while, Dai-chan begins talking to himself in a low voice. "Nagano, Nagano, we are now in Nagano. The train will depart in five minutes..." His intonation is just like that of a passenger conductor. So, you are remembering our long trip from Tokyo to here today, Dai-chan. It must have been an exciting experience for you. I know you like taking the train to school. You have learned by heart the order of the stations, haven't you? . . . I close my eyes, hearing Dai-chan's passenger-conductor-like talk. It takes me back to our trip, too.

Suddenly Tetsuro says,"Tokyo, Tokyo ..." His way of saying "Tokyo" mimics the announcement we hear at stations or in trains. But this unusually rapid and appropriate response surprises me. 
Dai-chan seems to be surprised too, because he stops his soliloquy. ... Were you listening to Dai-chan? Do you want to join us, Tetsuro? ... I look at him. He is lying toward me, touching his pillow. His eyes are open but he is not looking at me nor at anything else.

After a while Dai-chan starts his talking to himself again. Tetsuro also says "Tokyo, Tokyo," however, Dai-chan doesn't care about Tetsuro any more and continues his trip. So does Tetsuro, sometimes laughing in a low voice. Are they disturbing Aki? I feel Aki has not fallen asleep yet. But he doesn't say anything and lies still, as if he is also sharing this situation with Dai-chan and Tetsuro.

I feel I too am falling asleep, hearing them talking. Don't I have to go to the staff meeting? But that thought flies away from me as quickly as it came. I am half awake and half asleep. Lying still with my eyes closed, I no longer try to observe them nor to interpret their talks. I open myself to the whole situation or, the situation penetrates me. I don't care who is talking nor who is laughing (or do I?) I am falling down, down, down to sleep.

I wonder, remembering that evening, wherc I, or wc, went. We all fell asleep, of course. But what was that which I, or we, experienced in the very process of falling asleep? What was that situation I experienced between being awake and being asleep? It seems as if I had been in a situation into which everything in our room-myself, others (my three students), and the world-had melted.

Wallon introduces an analogous notion with what he calls "syncretic sociability." Syncretism here is the indistinction between me and the other, a confusion at the core of a situation that is common to us both. After that the objection of the body intervenes to establish a sort of wall between me and the other: a partition. Henceforth it will prevent me from confusing myself with what the others think. (Merleau-Ponty, M., 1964, p. 120)

I wonder if I experienced "syncretic sociability," a very primordial way of being, in the process of falling asleep that evening.

Here is another example about falling asleep which I observed as a mother.

I hear Asuka (my two year and seven month old daughter) crying for me in her bed where I left her about ten minutes ago. Her voice is not very loud but miserable enough to have me go and see. I approach her bedroom, feeling that she is looking at the door expecting my appearance. "What's the matter with you?" I ask. Crying even louder, she replies,"I can't sleep."

Asuka said that she couldn't sleep, which means that she had tried to sleep but failed. It had never occurred to her before that sleep can 
be elusive, although sometimes she did not sleep at the time her parents expected her to be sleeping. She has never before minded that she was not asleep, since she would just wait for sleep to visit her. Being unable to sleep was not a problem for her. But now, this evening, sleeping has become something to be sought after for her. Sometimes she may be able to sleep, but sometimes she may not. Besides, she finds it worrisome not to be able to sleep. She can't wait any more and tries to give herself to sleep.

Lying beside this little child, who is now sleeping with stains of tears on her cheeks, I talk to her in my mind, "You are growing up, aren't you?"

It was interesting to stay with her and watch her falling asleep when she was smaller. At first, she would play with me, tapping my shoulder and face or climbing up to my stomach. Then she would turn away from me, with her back toward me, touching and chewing her favorite blanket. Sometimes I would expect that she was about to fall asleep. But then, after a while, she would turn round to me suddenly and try to play with me again, this time with her blanket in her hand. Her eyes would tell me that she was very sleepy, yet she tried to be with me, as if she wanted to fall asleep with me, or as if she wanted me to fall asleep with her. She would hover between her own world and the world she shared with me. And finally, she would enter into her own world of sleep, leaving me, yet still feeling me beside her.

She used to spend most of her time with me. In this sense she shared her world with me and others most of the time while she was awake. Only when she fell asleep, she had her own world, even if she was unaware of it. It is impossible for us to fall into the world of sleep with someone else. In that sense we all have to fall asleep alone. And now, two year and seven month old Asuka knows somehow that she has to go to sleep all by herself, which makes her get upset and cry that she can't sleep. As her self becomes more clearly defined, the meaning of falling asleep for her must have changed. Thus questions occur to me: What was falling asleep like when she was smaller? What is it like now? How has the meaning of falling asleep changed? And what is falling asleep like anyway?

Everyone sleeps. In this sense it seems odd to ask what falling asleep is like. Yet there are many factors which make us wonder if we stop to think about it. For example, it is not yet known why people have to sleep. According to Buytendijk (1974), "in strong need of sleep, even after prolonged deprivation of sleep, we have not been able to indicate any functional deviations which can explain the need for sleep. ... And yet: it has been known for a long time that animals, who are kept awake for a long time, die" (p.110). Research has indicated some physiologically different state of body while being 
asleep; absence of muscle tension which is related to light (i.e., darkness decreases muscle tension), acoustical, olfactory, and sensory impressions; a particular body position in which the extremities are not stretched; the manner of breathing which is more passive and of longer duration; slower pulse beat; lower blood pressure; and lower concentration of adrenalin, and so forth (Buytendijk). Some of these factors we know through our experiences. When reading a book at a particular time of day, it would be much easier to fall asleep when we lie in bed (or even on the sofa) than when we sit on the chair in front of a desk. An unusual smell, such as of chemicals or of smoke in case of fire, may wake us up. Sirens of fire engines make a sleeping baby cry. Most travelers know that sleeping in an airplane is extremely uncomfortable, due perhaps to our seated position, engine sounds, or the pitching and rolling of the airplane. From these experiences, we know how to imitate the posture of sleep, to wait for it to come, lying on the bed in a dark room with our bodies relaxed.

These factors known both through our experiences and through physiological research may explain some aspects of falling asleep, but they do not tell us what it is like. For example, raising of the sensory thresholds is said to be one of the normal elements of sleep (Buytendijk, p. 107), but at the same time it is also well cited that a mother wakes easily to the sounds of her baby, even though other stronger sounds may not interrupt her. More generally, most of us know from our experiences that there are some nights when we find it difficult to fall asleep.

"The form of existence," as Buytendijk says, "thus changes sleep." The form of falling asleep depends on who you are, what you have (or have not) done today, how you feel, and where you are. Even though the physiological need for sleep may be the same, the form and the meaning of sleep may differ according to these factors. Buytendijk puts it this way:

A functional, basic organization ... is absorbed by the dialectical relation and polar unity of bodily and personal subjectivity. The integration (convergence) fields which are relevant-the formatio reticular and the cortex cerebri-can indeed be investigated objectively, but the meaning of the established facts can only-at least in part - be seen thoroughly in the context of existence. (p. 111)

We cannot, therefore, rely on physiology or biology, although it is undeniable that there are some physiological aspects in falling asleep. So the question remains: What is it like to fall asleep?

\section{Self and Others}

For example, I said, speaking for Asuka, that one had to fall asleep alone. But is that really true? Of course it is true in a sense that one 
cannot take an other person to the personal world of sleep. Everyone has a world of sleep which cannot be shared with others. Probably most of us have had an experience of being awake, listening to the breathing of a person who is sleeping beside us. But is it not also true that sometimes one cannot sleep alone? Do we not sometimes, like little Asuka, try to fall asleep with others, knowing that it is impossible, yet expecting that it might somehow make it easier to fall asleep (and sometimes it actually does!).

The presence of others does not necessarily have to be real. Even though you are in your bedroom alone, you may still feel that you are not lonely. You may hear voices of your family downstairs talking to each other peacefully. From the room next to yours, low sounds of music may be flowing, sometimes with a clattering of a chair, which reminds you of your big sister. You may smell the pipe of your husband smoking (he must be reading his favorite book with a cup of coffee, sitting on that comfortable sofa). Here come footsteps up to the front door, footsteps with a familiar rhythm which cannot be anybody else's but your father's. And you hear the door open. Each of these signs of absent presence could help us to fall asleep. It is a comfort in falling asleep to feel the presence of others we know close by.

Furthermore, there is a case in which one person's world of sleep is made with the help of another person; the case of a baby. During the first month after Asuka was born, it was not easy for me to soothe her while she was crying for sleep. I tried hard, carrying her, singing a lullaby, or walking around with her in my arms. But she did not stop crying, or worse, sometimes her cry would become harder, as if she felt, somehow, my confusion. Then it used to be my mother's turn. She would come to us and snuggle Asuka to her arms. She did, it seemed to me, at least at that time, more or less the same thing to Asuka as I did-rocking her gently, whispering comforting words, walking around with her, and so on. Gradually Asuka would calm down into sleep. It seemed as if Asuka had been waiting for her grandmother, instead of her brand-new mother. I used to wonder, looking at my mother with my daughter in her arms, why she could coax my daughter into sleep so easily when I could not. Both my mother and my daughter looked very relaxed and comfortable, which made me feel left out. I remember my mother telling me, recognizing the unsatisfied expression in my face, "It's all right. Soon you will become the one who can put Asuka to sleep best."

Three months later when my mother came to visit us, I found that she had been right. This time it was I, not my mother, who could soothe our crying baby to sleep. Everything seemed to be the same: my mother did the same thing to my daughter as she used to; I did the same thing as I used to; there seemed to be no obvious difference between what my mother did and what I did-rocking the baby, 
patting her back gently, talking to her in a quiet voice, and so on. Yet it was not until I took her into my arms from my mother's that she started to calm down. Her tension decreased gradually in my arms. Crying changed into gentle uttering, and her body which had bent backward now snuggled into my arms. It seemed that she noticed the differences between my mother and me behind the apparent sameness of our activities. It was as if she had known me through her body.

Almost all mothers can let their own babies fall asleep best. ${ }^{1}$ It does not necessarily mean that a mother is particulary good at carrying babies in general, that she knows a technique, but it does mean that a mother is good at carrying her baby.

As we have seen in the example above, my mother could let my daughter fall asleep better than I could just after her being born. The example also leaves the possibility open that my mother would be able to let a baby fall asleep more easily than $I$ if the baby is not mine. It might also be possible that persons who have brought up children can put babies to sleep better than those who have not. So we are not denying, in this sense, that there are some physiological factors in falling asleep, which are the basis of a generalized knowledge. But the point here is that, regardless of those factors, a mother can carry her baby and let her fall asleep better than others, that a baby seems to be more comfortable with her mother than with anybody else. In other words, a mother has come to attune herself to her baby and, probably more importantly, a baby has come to attune herself to her mother; thereby a particular resonance between each mother and her baby has been built up. We see in the process of the baby's falling asleep the mother's becoming her baby's mother and a baby's becoming her mother's baby. It seems like mother and baby have made together a shared world of sleep.

As we have seen, one cannot enter into sleep with others, yet there are times when one does not fall asleep alone. The manifestation of another's presence may vary by one's age, or one's mood of the day. But one needs, at times, some kind of another's presence for comfortable sleep, whether or not ("in spite of" and sometimes "because of") one knows that one cannot share the world of sleep.

One might say that there are those persons who live alone yet have no difficulties with falling asleep alone, which we do not deny. We could indicate two points with respect to those persons. First, one's manifest relation with others is not the only factor we can see in falling asleep. As we will see later, there are other aspects to be considered in terms of falling asleep. In this regard, it is quite possible that one falls asleep comfortably surrounded by familiar and intimate things, or comforted by an atmosphere which one has made oneself 
and which assures peaceful sleep. Secondly, as we have seen, another's presence can be "absent presence." A memory of your mother; a birthday card on the table which reminds you of your friend; an appointment with a friend tomorrow; all of these things would give you the feeling of other's presence. But as far as we see falling asleep in terms of one's relations with others, we could say that there are two extremes: on the one hand, one cannot share the world of sleep with others; on the other hand, at least at times, one cannot sleep alone. A sleeping person is somewhere between these two extremes with respect to one's relations with others.

\section{One and Self}

Van den Berg writes about a sleeping person as follows:

He erases the leftovers of the day from his mind except the most pleasing ones, or he loses himself in the unbridled fantasies of pleasantness. Sleep arrives. Sleep is the systole, the construction of his existence, his coming to self and his losing of himself within himself, and the bed is the place of systole. (van den Berg, 1980, p. 61)

We can see, in this description, a peculiar mode of awareness. The self is lost when sleep falls. One is no longer conscious of oneself. All the activities concerning oneself cease. Everything is left "there" outside oneself; work, hope, desire, worries, troubles, happiness, unhappiness, regrets, joy, grief ... everything. One leaves oneself and forgets about it.

But this does not mean that a person stops being a self. In a sense it is even said that one comes to oneself when one falls asleep. One is not bothered by anything any more-others, things, and concerns -and goes back to one's own self. When he falls asleep, a boy is no longer a boy who made a terrible mistake today and was in the dumps. A mother is no longer a mother who had scolded her child for a trivial mischief and felt guilty for it. An athlete is no longer an athlete who won the game and was filled with joy today. Or, when she falls asleep, a girl is not yet a girl who is going to have great fun with her friends tomorrow. Between today and tomorrow, one is simply oneself, and this being oneself is made possible by losing oneself. In this sense a man falling asleep is "his coming to himself and losing of himself within himself."

\section{Self and World}

The sleeping person is not isolated; the world is condensed within him. He "forgets" about it, he makes the world wait for him, he puts everything "between brackets." "Tomorrow" is the distance he creates between all things and himself, a distance which assures a complete rest. He lacks nothing; on the contrary he has gathered everything into a silence. (van den Berg, 1980, p. 62) 
Indeed, when we fall asleep, we leave everything behind us: work, the cups we use so often that sometimes they look as if they are part of ourselves, the living room with familiar things-our world. In this sense falling asleep is a withdrawal from the world we live in. But, as van den Berg says, this withdrawal is not a negative one. We "forget" about it and let it wait for us, but that is just in order to remember it and meet it again next morning. We do it because we do not doubt that the world will wait for us nor that it will not totally change while we are sleeping. Falling asleep is normally a restful and comfortable withdrawal from the certainty of the world.

Yet falling asleep is also being caught by the world.

To fall asleep is, in a sense, a withdrawal to the self from the world. But this is only a part of the truth. When we lie down and relax our bodies to sleep, we are caught by the world, giving ourselves to the earth.

(Shimoyama, 1975, p. 179)

When we fall asleep, we leave everything and withdraw ourselves from the world. But it is also true that we sleep in the world. This is mainly because we exist in bodies; we cannot abandon our bodies even while we are sleeping. Even though we withdraw ourselves from the world and let it wait during the sleep, our bodies remain in the world. In this sense it could be said that we are caught by the world when we fall asleep. Of course there are many ways of being caught by the world. For many people who have healthy and restful sleep, falling asleep would be more like being protected by the world, than being caught. A body is wrapped by a greater existence than itself, which assures the safe and restful sleep. On the other hand, there might be a person who is in deep grief and wishes to forget everything and never to remember it again. Such a person escapes at least temporarily from the world by falling asleep, in the hope of never waking up again. But this cannot happen, since embodied existence cannot be erased by falling asleep. One continues to be oneself disparately, even while sleeping. For such a person sleep is literally the experience of being caught by the world. It is a temporary refuge from the threatening world, awareness of being caught by the world is all the greater upon awakening. In any case we could say that falling asleep is a withdrawal from the world but that this withdrawal is one which is both from the world and into the world.

In falling asleep, therefore, we experience three peculiar polarities: we cannot fall asleep with other persons, yet we cannot fall asleep alone; we leave ourselves when we fall asleep, yet we come to ourselves by losing ourselves within ourselves; and, we withdraw ourselves from the world yet are caught by the world. When falling asleep, one's "tension of consciousness" is loosened from higher de- 
grees to the lowest degree (Schutz, 1962). Those who have no difficulty with falling asleep settle down to a place where these complex polarities keep subtle balance, wherever they may have been between these polarities while awake. Such a person is not too concerned about others nor feels too lonely to fall asleep, and can become lost within the self letting the world wait until tomorrow without any difficulty. In other words, everything can be forgotten until waking up when life is continued after a restful discontinuitysleep. Besides, and probably more importantly, one is not conscious of all these things. This unawareness of being able to forget everything makes it possible to fall asleep. And when one cannot be unaware of it, it is found to be difficult to fall asleep. We exist in relationships to ourselves, to others, and to the world. Each of these represents a place of extremes, any of which could easily cause sleeplessness. One who has trouble in falling asleep might be too lonely, or, on the contrary, might feel (or wish to feel) too close to someone. Such a person might be too conscious of self-of grief, of one's own problem, of others or the world-and cannot find the appropriate place for falling asleep.

It seems that this conscious awareness of her relationship with herself, others, and her world made Asuka cry that she could not sleep. When she was smaller she was not aware of these relationships because her sense of self had not been developed clearly enough to recognize a difference between herself and the outer world including others. It had not been until that evening she cried that she somehow noticed this difference. And when she noticed it, she could no longer be naive; she could no longer wait for sleep to fall upon her as it used to. Indeed, as she expressed, it was not that she didn't sleep nor wouldn't, but that she couldn't. Thinking from this point of view, we could recognize her cry of "I can't sleep" as a landmark on a long way of her development; a landmark between a state where "the me is both entirely unaware of itself and at the same time all the more demanding for being unaware of its own limits" and a state where "me . . . is a me that knows its own limits yet possesses the power to cross them by a genuine sympathy that is at least relatively distinct from the initial form of sympathy" (Merleau-Ponty, 1964, p. 120).

"Okay, Asuka, the story is over. Now go to sleep, and have a good sleep," I say to Asuka after having read a bed time story. "Big hug and a big kiss" she says and we do. We wave to each other, saying "good night." When I leave her room I turn toward her and say "good night" again. Then she says, "Leave the door open. And you will come to me when I feel lonely, won't you?" She smiles when I assure her, then turns around toward the wall, touching her blanket. She does not need my physical presence and can fall asleep with the assurance of my absent presence-although, sometimes, she still 
wants me to stay with her until she falls asleep. She needs the door to be open. That door is a bridge between her and me. She can feel that she is not alone with that open door. Someday, she may no longer need the door open. Yes, she is growing up. Have a good sleep, Asuka!

\section{Note}

1. We are discussing this matter in terms of a baby's relation with only her mother here, partly because my reflection is based on my own experience as a mother, and partly because it can be seen between a baby and a mother most commonly. But, needless to say, a mother here can be a father or a significant person to a baby.

\section{References}

Buytendijk, F.J.J. (1974). Prolegomena to an anthropological physiology. Pittsburg: Duquesne University Press.

Merleau-Ponty, M. (1964). The primacy of perception. Evanston: Northwestern University Press.

Schutz, A., (1962). The problem of social reality: Collected papers 1. The Hague: Martinus Nijhoff Publishers.

Shimoyama, T. (1975). Kasho no sekai (The world of appearance). Tokyo: Shisaku-sha.

Van den Berg, J.H. (1980). The psychology of the sickbed. New York: Humanities Press. 